\title{
IUMRS-ICEM-98 Convenes in Korea
}

The International Union of Materials Research Societies (IUMRS) sponsors the International Conference on Electronic Materials (ICEM) in even-numbered years, and the International Conference on Advanced Materials (ICAM) in oddnumbered years. The Union holds its business meeting at these conferences, which are hosted by an IUMRS Adhering Body.* This year, ICEM was hosted by the Materials Research Society of Korea (MRS-K), on the volcanic island of Cheju, from August 24 to 27. The chair and key members of the conference organizing committee were Soon Ja Park, Shinhoo Kang, and Hyeong Joon Kim from Seoul National University, Chong Oh Kim from ChungNam National University, and Sang Yun Lee from Kyungbook National University.

IUMRS is tied together by a common philosophy and focus on interdisciplinary, symposium-based technical meetings. ICEM-98 comprised 10 symposia in five parallel sessions, replete with four plenary talks, 26 invited lectures, a very active poster session offering 205 presentations, 238 oral presentations, and a small vendor exhibit. The conference drew 700 participants. The registration lobby was graced by a black BMW Z3 roadster which gave a brief glimmer of hope that a prize or lottery was being offered, but alas the car was only there as part of a promotion agreement between the hotel and a BMW dealership.

Symposia were held on (A) Silicon Process; (B) Compound Semiconductors for Electronic \& Photonic Devices; (C) Electroceramics and Sensors; (D) Display Materials; (E) Magnetics; (F) Ferroelectric Thin Films; (G) Electro-Packaging; $(\mathrm{H})$ The Surface, Interface, and Nanostructure of Materials; (I) Polymers for Electronics; and (J) Energy Conversion and Storage Materials. The emphasis of the program leaned toward applications and industrial practice, which clearly reflects the manufacturing base of the Korean economy. Of the 440 papers presented at the meeting, 337 were of Korean origin and many of these were from industrial laboratories. Non-Korean participation at the meeting was not as great as the organizers had originally hoped. Most likely the uncertain state of the Korean economy gave many potential participants pause for thought, but eventually the weakness of the Korean Won made the trip a real bargain for those who traveled from outside of Asia.

\footnotetext{
*This is the officially sanctioned term for a "member organization."
}

The content of the papers varied from descriptions of processing "recipes" to sophisticated models of materials behavior, and participants who were able to attend enough of the presentations gained some insight into the issues of general concern, particularly to the

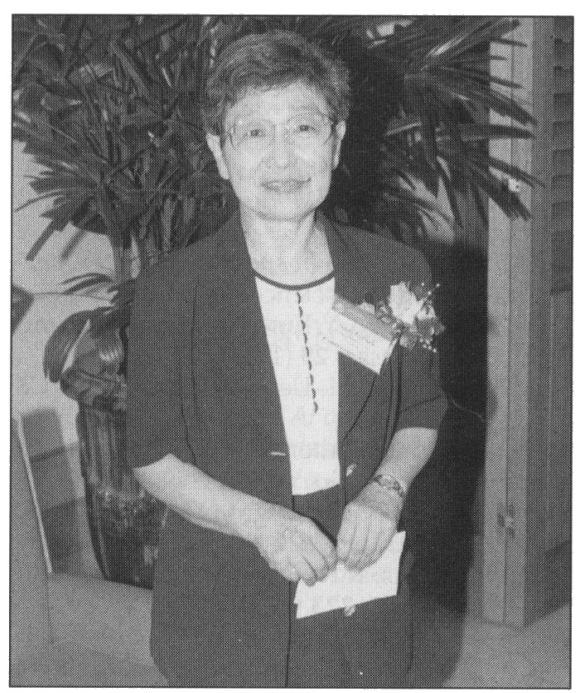

Soon Ja Park, president of the Korean Materials Research Society (MRS-K), chairs the 1998 International Union of Materials Research Societies-sponsored International Conference on Electronic Materials (IUMRSICEM-98) held August 24-27 in Korea.

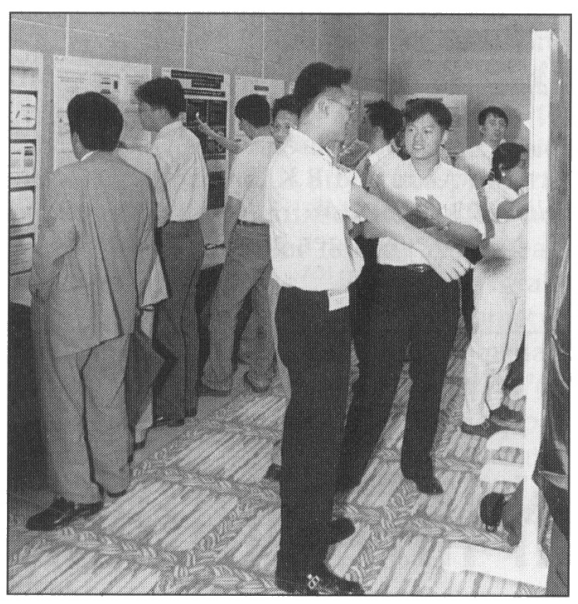

Participants visit the 205 poster presentations given at the 1998 International Union of Materials Research Societies-sponsored International Conference on Electronic Materials (IUMRS-ICEM-98) held August 24-27 in Korea.
Korean electronic materials community. Korea has a tradition of dominance in the "memory" market but is now trying to switch its emphasis more toward devices. Work on memory-related materials is still very apparent, and very mature. The learning curve has a steeper gradient in the device area. The symposium on Energy Conversion and Storage Materials was a clear acknowledgment of the importance of conservation, and was supported by a plenary lecture from the University of Tokyo's Ryoichi Yamamoto. This area is receiving significant governmental backing in some of Asia's industrial nations; and although it is somewhat unfocused compared with other typical symposium topics, clearly a great deal of work needs to be done by those with the vision on how to proceed. An interesting feature of Yamamoto's talk was a description of a recyclable house: This is the first time I have seen a consideration of the recyclability of something as permanent as a building. Perhaps houses are not seen as permanent objects in earthquakeprone Japan, or perhaps a new paradigm is under construction. Other plenary talks were presented by Allan Heeger, University of California-Santa Barbara, on semiconducting polymers and their applications in displays; I.K. Hwang, CEO of ANAM Semiconductor, Korea, on trends in packaging; and MRS President Bob Nemanich, North Carolina State University, on interface instability in SiGe alloys.

The ICEM-98 meeting accommodated a banquet (Western style) followed by a program of traditional Korean music. Presidents of the Korean Ceramic Society, IUMRS, and Cheju National University, and the Governor of Cheju Province each delivered congratulatory speeches. A cultural outing to a reconstructed folk village provided some interesting insight into earlier life on Cheju, and the constraints of its volcanic geography. Those same constraints now make Cheju one of the great undiscovered tourist destinations of the world with spectacular scenery, water sports, golf, horseback riding, and many other activities.

Summaries of the symposia will appear in the Korea Journal of Materials Research. Proceedings of the conference will be published at the end of this year in a special issue of the Journal of Korea Physical Society.

ALEX KING

MRS International Affairs Subcommittee Chair With contributions by H.J. KIM ICEM Organizing Committee 